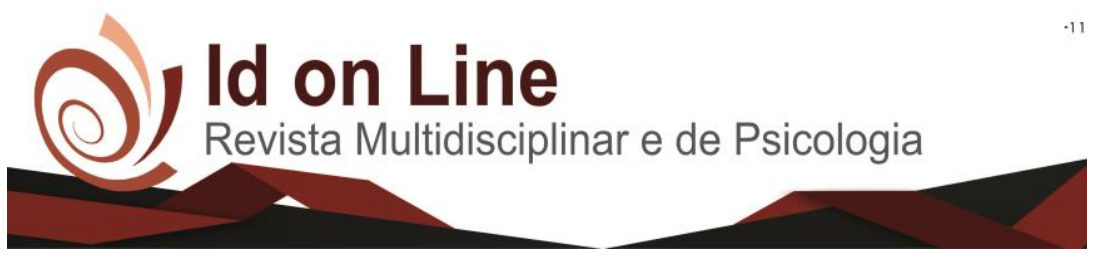

DOI: 10.14295/idonline.v13i46.2004

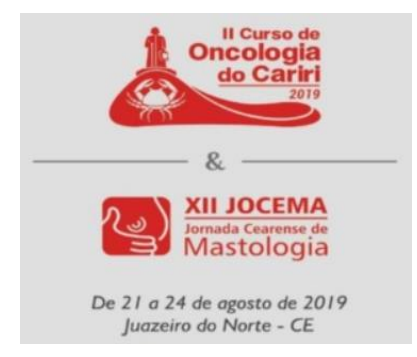

Resumo

\title{
EPENDIMOMA INTRADURAL E EXTRAMEDULAR: RELATO DE CASO
}

\author{
Pedro Walisson Gomes Feitosa ${ }^{1}$; Raysa Siqueira Vieira ${ }^{2}$; Ricardo Brandão Fonseca ${ }^{3}$; \\ Alyne Oliveira Correia ${ }^{4}$ Tiago Gomes Pires ${ }^{5}$
}

Introdução: Os ependimomas constituem cerca de $60 \%$ dos tumores espinais intramedulares. No entanto, a localização intradural e extramedular dessas lesões é rara. Ependimomas comumente tem uma localização intramedular, pois derivam de células ependimárias, localizadas no canal central do cordão espinhal. A incidência é maior na idade adulta e com predileção pelo sexo feminino. O sítio mais comum de ocorrência é no segmento torácico da coluna vertebral. A RNM é o método de escolha na maioria dos casos. A exérese cirúrgica completa é possível, tratando-se de lesões encapsuladas, bem vascularizadas, porém pouco aderidas ao cordão espinhal, raízes ou dura-máter. Objetivo: Descrever um caso raro e evolução de ependimoma intradural e extramedular. Relato de Caso: Paciente com 48 anos de idade, do sexo masculino, foi admitido com quadro álgico em cintura escapular, evoluindo inicialmente com paresia em MSD, progressiva, acometendo posteriormente o MSE, de início há um ano anterior a admissão. Em outro serviço foi solicitado Eletroneuromiografia de MMSS, que mostrou radiculopatia cervical, mais evidente em C7-C8 à direita. Realizou-se tratamento clínico, todavia, houve piora do quadro, decorrendo com tetraparesia progressiva até interrupção da deambulação. Ao exame, apresentavase em GSC 15, com hipotrofia de musculatura intrínseca de mãos, tetraparesia flácida grau 2, dor articular à movimentação de membros. Realizou RNM de coluna cervical que evidenciou lesão expansiva intrarraqueana e extramedular, ocupando o segmento anterior do canal, medindo cerca de $100 \mathrm{~mm}$ de extensão, desde C2-T1, que produziu compressão medular, contudo, sem hipersinal intramedular. $\mathrm{O}$ paciente foi submetido à abordagem cirúrgica por via posterior com exérese completa da lesão. O resultado de avaliação anátomopatológica mostrou-se sugestivo de Ependimoma (GRAU II da OMS), confirmado por imunohistoquímica. Paciente recebeu alta com melhora parcial do quadro, em GSC 15, tetraparesia grau 3. Conclusão: Em nosso caso, realizouse uma abordagem por via posterior, com exérese completa da lesão, sem déficits adicionais. A importância do seguimento após procedimento justifica-se pelo risco de recorrência e transformação maligna dessas lesões. Portanto, os ependimomas devem ser incluídos como diagnóstico diferencial das lesões intradurais e extramedulares, bem como a exérese completa da lesão é o tratamento padrão-ouro, seguido de radioterapia adjuvante nos casos que cursem com transformação maligna.

Palavras-chave: Ependimoma intradural; Ependimoma extramedular; Tratamento cirúrgico.

\footnotetext{
${ }^{1}$ Acadêmico de Medicina pela Universidade Federal do Cariri

${ }^{2}$ Residente de Neurocirurgia pelo HU-UNIVASF

${ }^{3}$ Neurocirurgião no HU-UNIVASF

${ }^{4}$ Residente de Neurocirurgia pelo HU-UNIVASF

${ }^{5}$ Neurocirurgião no HU-UNIVASF
} 


\section{Referências}

PEGO-FERNANDES, PAULO MANUEL et al . Ependimoma metastático de pulmão. J. Pneumologia, São Paulo, v. 27, n. 5, p. 282-284, Sept. 2001 .

TORRES, LUIZ FERNANDO BLEGGI et al . Ependimomas: achados clínicos, epidemiológicos e anatomopatológicos de 22 casos. Arq. Neuro-Psiquiatr., São Paulo, v. 57, n. 2A, p. 261-266, June 1999 . 